This article is a preprint and is submitted to a peer-review journal. Subsequent versions of this article may have slightly different content after a peer review. When published, the final version of this article will be available via the 'Peer-reviewed Publication DOI' link on the right-hand side of this webpage. Please feel free to contact the author; I welcome any feedback. 


\title{
Sensitivity of evapotranspiration deficit index to its parameters and temporal scales
}

\author{
Frank Joseph Wambura \\ Department of Urban and Regional Planning, \\ Ardhi University, P.O. Box 35176, Dar es Salaam, Tanzania. \\ E-mail: frank.wambura@aru.ac.tz or wamburafj@gmail.com
}

\begin{abstract}
Sound estimates of drought characteristics are very important for planning intervention measures in drought-prone areas. Among many drought indices used in estimation of drought characteristics in many parts of the world, evapotranspiration deficit index (ETDI) is increasingly used to estimate agricultural drought. However, in most studies ETDI has been computed using the specific ETDI formula. Thus, there is no clear information about sensitivity of ETDI to its parameter and temporal scales. In this study, the general ETDI formula homologous to the specific ETDI formula was introduced and used to test sensitivity of ETDI to its parameters and temporal scales using time series of remotely sensed evapotranspiration data in the Ruvu River basin (Tanzania). The parameter sensitivity test revealed that ETDI is sensitive to its parameters. Different parameter combinations resulted into different drought characteristics. In order to reduce this uncertainty, the general ETDI formula might require parameter calibration. On the other hand, the temporal scales sensitivity test showed that drought characteristics such as number of drought events and the total drought durations decreased as the size of temporal scales increased. Thus, inappropriate temporal scales may lead to misrepresentation of drought characteristics. In order to increase accuracy of drought characteristics derived from ETDI, small temporal scale data are highly recommended. Therefore, this study has provided useful information for improving application of ETDI in estimation of agricultural drought characteristics.
\end{abstract}

Keywords: Agricultural drought; Drought characteristics; Evapotranspiration deficit index; Parameter sensitivity; Temporal scale sensitivity; Water stress anomaly

\section{Introduction}

Drought is an environmental disaster that brings severe social, economic, and environmental impacts around the world. Thus, drought is usually categorized into four main operationbased types, namely, meteorological drought, hydrological drought, agricultural drought and socio-economic drought (Ali et al. 2015; Bayissa et al. 2018; Wilhite et al. 2007; Zargar et al. 2011; Ziolkowska 2016). Since drought is often caused by decrease of precipitation below the normal amount, agricultural productivity is usually the most affected due to its direct dependence on water resources especially soil moisture. Drought begins when soil moisture available to plants drops to a level that adversely affects the crop yield and consequently agricultural production (Martínez-Fernández et al. 2016; Panu and Sharma 2002). The decline of agricultural productions indirectly causes critical issues such as food insecurity 
which may eventually lead to socio-economic consequences. For that reason, understanding agricultural drought is vital for planning mitigation and adaption measures in areas susceptible to drought.

Several indices have been developed to estimate agricultural drought using various water balance parameters. Most of these indices use precipitation data, temperature data, actual evapotranspiration (ET) data, potential evapotranspiration (PET) data, crop characteristics, crop management practices etc. (Hao and Singh 2015; Martínez-Fernández et al. 2015; Touma et al. 2015; Yang et al. 2017). One of the prominent drought indices is evapotranspiration deficit index (ETDI) (Narasimhan and Srinivasan 2005). ETDI uses ET and PET data for estimating short-term agricultural drought (Narasimhan and Srinivasan 2005). ETDI can be scaled between -2 and +2 to compare with standardized precipitation index (Li et al. 2015; Pramudya and Onishi 2018; Šebenik et al. 2017; Shah et al. 2015; Trambauer et al. 2014) or between -4 and +4 to compare with Palmer drought severity index (John et al. 2013). Details about other drought indices is found in the studies by Sivakumar et al. (2011) and Zargar et al. (2011).

ETDI has been widely used to estimate drought in many parts of the world. Narasimhan and Srinivasan (2005) used ETDI for monitoring agricultural drought of six watersheds located in major river basins across Texas, United States. Trambauer et al. (2014) used ETDI to analyse hydrological drought in the Limpopo River basin, southern Africa. Esfahanian et al. (2017) used ETDI and other drought indices to develop a comprehensive drought index. Bayissa et al. (2018) used ETDI in comparisons of drought indices in the Upper Blue Nile Basin, Ethiopia. In all those studies, ETDI was computed using the specific ETDI formula, thus sensitivity of ETDI to its parameters and temporal scales is hardly known.

Therefore, the objective of this study was to investigate sensitivity of ETDI (1) to its parameters, and (2) to temporal scales. To address this objective, firstly the general ETDI formula homologous to the specific ETDI formula was introduced. Then by using the general ETDI formula, sensitivity of ETDI to its different parameter combinations was tested. Finally, sensitivity of ETDI to different temporal scales (i.e., 8-days, 16-days and 1-month) was also tested under constant parameter combination.

The layout of the rest of the paper is as follows: Section 2 provide explanations about the case study, main data used, evapotranspiration deficit index approach, parameter sensitivity test and temporal scale sensitivity test. Section 3 presents results and discusses findings about parameter sensitivity and temporal scale sensitivity. Finally, Section 4 draws conclusions about findings and offers an outlook on future applications of the general ETDI formula in drought analysis studies.

\section{Material and Methods}

\subsection{Case study}

The case study used was the Ruvu River basin. The Ruvu River basin is located between $6^{\circ} 18^{\prime} \mathrm{S}-7^{\circ} 46^{\prime} \mathrm{S}$ and $37^{\circ} 15^{\prime} \mathrm{E}-38^{\circ} 58^{\prime} \mathrm{E}$ in east Tanzania (Fig. 1). Its headwaters originate on the eastern slopes of the Uluguru Mountains and descends northeast towards the coast in a swampy estuary at the Indian Ocean. The basin area is approximately $17,693 \mathrm{~km}^{2}$ and its elevation ranges between 4 and 2636 metre above sea level (Fig. 1, Jarvis et al. 2008). The average daily temperature in the basin is between $22^{\circ} \mathrm{C}$ and $24^{\circ} \mathrm{C}$, whereas the mean annual rainfall ranges from $800 \mathrm{~mm}$ to $2000 \mathrm{~mm}$ (Kashaigili 2011). 


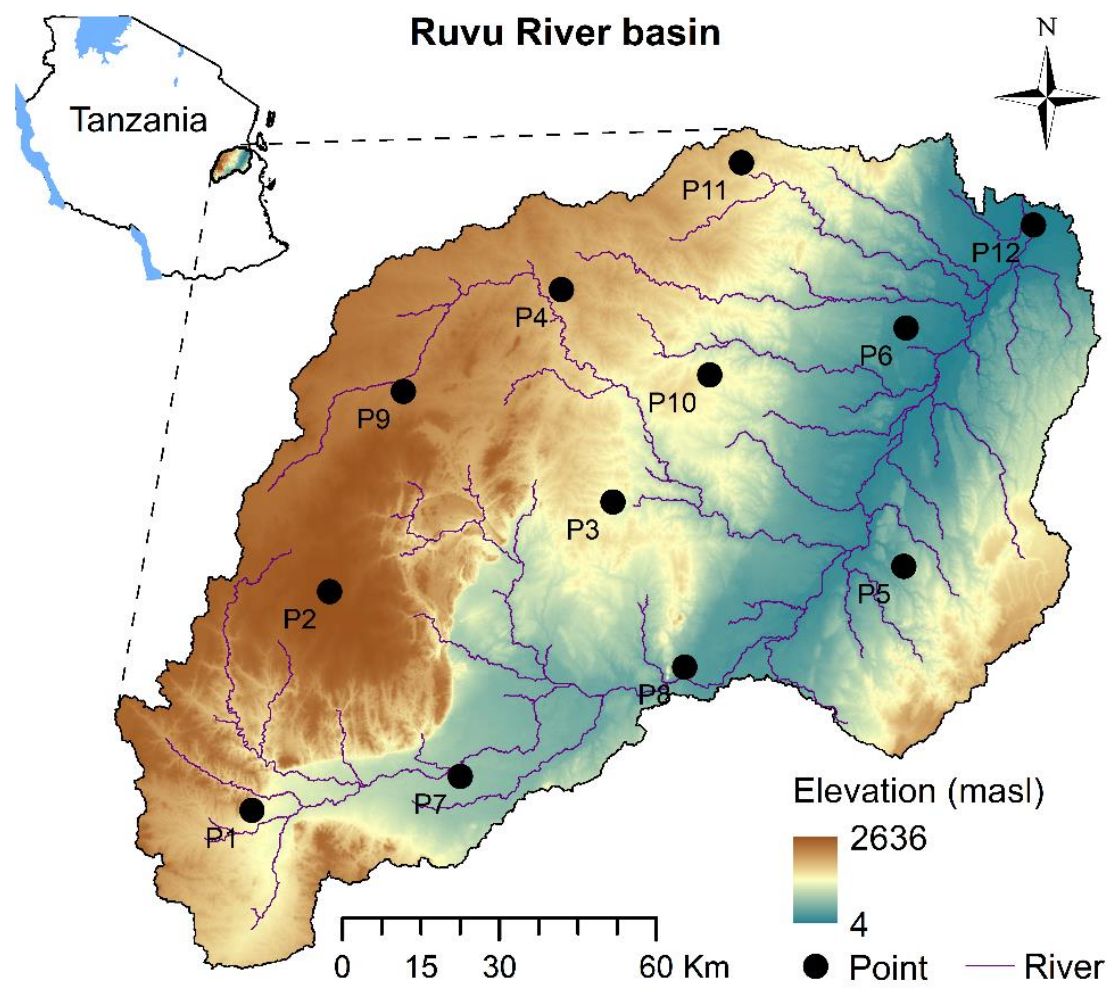

Fig. 1. The Ruvu River basin showing points (P1 to P12) used to extracted time series of evapotranspiration and potential evapotranspiration from remote sensing images.

This region of coastal Tanzania is also known to have frequent and intense drought episodes (Hassan et al. 2014). Thus, the river basin has very dynamic weather system. The Ruvu River basin was selected to be a case study because dynamic weather systems are often very sensitive to even small changes.

\subsection{Main datasets used}

Due to data-scarcity in this region, ET and PET data used in this study were obtained from the MODerate resolution Imaging Spectroradiometer (MODIS) imagery program (Mu et al. 2011). Remotely sensed ET and PET data from the MODIS programme was MOD16A2-v5 (from now on MODIS ET) available at spatial resolution of 1-km and temporal resolution of 8-days and 1-month. The first dataset consisting of 690 images of 8-days MODIS ET covering the Ruvu River basin was downloaded from the NTSG repository (http://files.ntsg.umt.edu/data/NTSG_Products/, accessed on 15 October 2017). Another dataset consisting of 690 images of 1-month MODIS ET covering the river basin was also downloaded from the same repository on 10 July 2019. Each of the two datasets of MODIS ET images spanned between the years 2000 and 2014.

Each of the twelve points (P1 to P12) spatially distributed in the Ruvu River basin (Fig. 1) were used to extract two pairs of time series from the MODIS ET datasets. Firstly, the twelve points extracted ET and PET time series from the 8-days MODIS ET dataset. Then the 8-days time series of ET and PET were aggregated to form the 16-days time series. The convertion to 16-days timestep was necessary because MODIS ET products are only available at 8-days and 1-month timesteps. Finally, the twelve points were also used to extract monthly ET and PET time series from monthly MODIS ET dataset. Figure 2a-c shows the 8-days, 16-days and monthly ET and PET at point P1 for illustration purposes. 

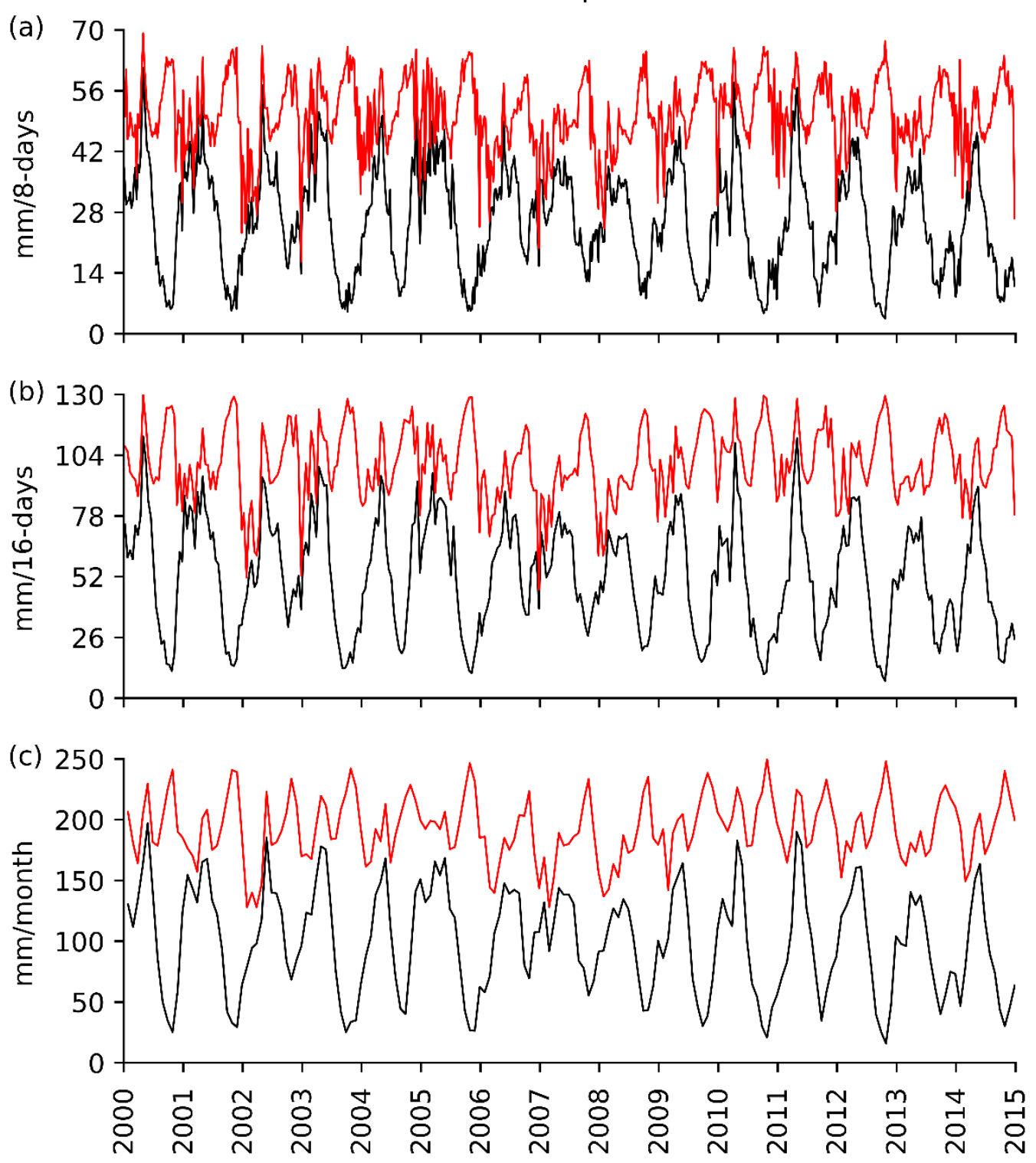

Fig. 2. Typical MODIS evapotranspiration (ET) and potential evapotranspiration (PET) time series at 8-days, 16-days and 1-month temporal scales (Mu et al., 2013) for point P1 in the Ruvu River basin.

\subsection{Evapotranspiration deficit index approach}

The ETDI approach involves three steps, firstly estimation of water stress (WS), then estimation of water stress anomaly (WSA) and finally estimation of ETDI. Estimation of WS of a point (e.g., P1) in the river basin was done using Eq. (1) (Bayissa et al. 2018; Narasimhan and Srinivasan 2005). WS ranges from 0 (ET is the same as PET) to 1 (no ET).

$$
W S_{i, j}=\frac{P E T_{i, j}-E T_{i, j}}{P E T_{i, j}}
$$

Where, the subscript i represents a period (i.e., an 8-days, 16-days or 1-month) in year j. The subscript $j$ ranges between the years 2000 and 2014 with a timestep of one year. 
Then, WSA of the same point in the river basin was estimated using Eq. (2) (Narasimhan and Srinivasan 2005), where min WS, med WS and max WS are long-term minimum, median and maximum of WS values at time t from all years in the time series. Equation (2) removed seasonality inherent in the time series of WS. WSA ranges from -1 to +1 indicating very dry to very wet conditions, respectively.

$$
W A_{i, j}= \begin{cases}\frac{\operatorname{med} W S_{i}-W s_{i, j}}{\operatorname{med} W S_{i}-\min W S_{i}} & \text { if } W S_{i, j} \leq \operatorname{med} W S_{i} \\ \frac{\operatorname{med} W S_{i}-W S_{i, j}}{\max W S_{i}-\operatorname{med} W S_{i}} & \text { if } W S_{i, j}>\operatorname{med} W S_{i}\end{cases}
$$

Narasimhan and Srinivasan (2005) invented the specific ETDI formula which states that, at a particular point in time the current ETDI $\left(\mathrm{ETDI}_{\mathrm{t}}\right)$ is the sum of half of the previous ETDI $\left(\mathrm{ETDI}_{\mathrm{t}-1}\right)$ and the current WSA $\left(\mathrm{WSA}_{\mathrm{t}}\right)$ (Eq. A1 in Appendix A). Although the specific ETDI formula shows that ETDI $\mathrm{t}_{\mathrm{t}}$ linearly depends on both $\mathrm{ETDI}_{\mathrm{t}-1}$ and $\mathrm{WSA}_{\mathrm{t}}$, the coefficient of the latter was ignored or assumed unit. Moreover, the constant term (intercept plus error) was also not addressed by Eq. (A1). In this study, the general ETDI formula was introduced as a multivariate linear equation homologous to the specific ETDI formula. The general ETDI formula has three variables and three unknown coefficients including the constant term (Eq. 3). Therefore, the specific ETDI formula (Eq. A2 in Appendix A) is a special case of the general ETDI formula (Eq. 3).

$$
\mathrm{ETDI}_{\mathrm{t}}=\alpha \mathrm{ETDI}_{\mathrm{t}-1}+\beta \mathrm{WSA}_{\mathrm{t}}+\gamma
$$

Where, $t$ represents continous timestep (it replaced period $i$ in year j from Eq. 2). $\alpha$ modulates the long-term memory of ETDI. $\beta$ converts WSA value into ETDI and $\gamma$ is the constant term.

By considering that ETDI is scaled between -2 and +2 like the standard precipitation index (Bayissa et al. 2018; McKee et al. 1993), therefore, at very dry boundary condition, consecutive dry periods have $\mathrm{WSA}_{t}$ equals to $-1, \mathrm{ETDI}_{\mathrm{t}}$ and $\mathrm{ETDI}_{\mathrm{t}-1}$ equal to -2 . Likewise at very wet boundary condition, consecutive wet periods have $W_{S A}$ equals to $+1, E T_{D I}$ and ETDI $_{t-1}$ equal to +2 . By substituing these two boundary conditions in Eq. (3) then $\gamma$ becomes 0. Therefore, the general ETDI formula (Eq. 3) becomes Eq. (4). At initial condition, ETDI $\mathrm{t}_{\mathrm{t}-1}$ was considered to be zero.

$$
\mathrm{ETDI}_{\mathrm{t}}=\alpha \mathrm{ETDI}_{\mathrm{t}-1}+\beta \mathrm{WSA}_{\mathrm{t}}
$$

By substituging either of the boundary conditions (i.e., very dry or very wet), Eq. (4) turns into a parameters equation which governs the relationship between $\alpha$ and $\beta$ parameters (Eq. 5). Figure 3 shows the straight line of Eq. (5).

$$
\beta=-2 \alpha+2
$$

Equation (5) indicates presence of large number of parameter combinations along the straight line. Table 1 shows ranges of $\alpha$ and $\beta$ parameters at consecutive extreme dry and wet conditions. Thus, for the values of ETDI in Eq. (4) to span between -2 and +2 , values of $\alpha$ should range between 0 and 1 , and values of $\beta$ should range between 0 and 2 (Eqs. 4 and 5, Fig. 3, Table 1). Therefore, ETDI time series at a point in the river basin for subsequent analyses was estimated using Eq. (4) and parameters were governed by Eq. (5). An ETDI time series derived using $(\alpha, \beta)$-parameters is hereafter referred as an $\operatorname{ETDI}_{(\alpha, \beta)}$ time series or curve. 


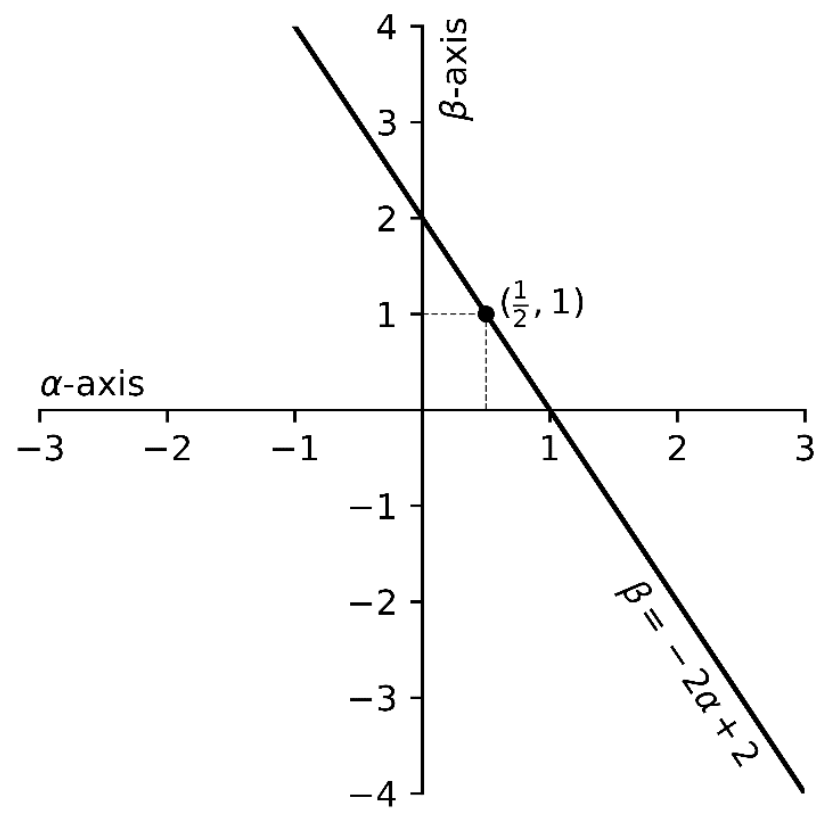

Fig. 3. Straight line representing extreme dry and wet conditions using $\alpha$ and $\beta$ parameters as coefficients of previous evapotranspiration deficit index and current water stress anomaly, respectively.

Table 1: Evapotranspiration deficit index (ETDI) of a point in time $(\mathrm{t})$ at boundary conditions of extreme dry and wet conditions for three different range of $(\alpha, \beta)$-parameter combinations.

\begin{tabular}{llllll}
\hline Extreme & ETDI $\mathbf{- 1}$ & WSA $_{\mathbf{t}}$ & ETDI $_{\mathbf{t}}$ at $(\boldsymbol{\alpha}<\mathbf{0}, \boldsymbol{B}>\mathbf{2})$ & ETDI $_{\mathbf{t}}$ at $(\mathbf{0} \leq \boldsymbol{\alpha} \leq \mathbf{1}, \mathbf{2} \geq \boldsymbol{B} \geq \mathbf{0})$ & ETDIt $_{\mathbf{t}}(\boldsymbol{\alpha}>\mathbf{1}, \boldsymbol{\beta}<\mathbf{0})$ \\
\hline Dry-Dry & -2 & -1 & -2 & -2 & -2 \\
Wet-Wet & +2 & +1 & +2 & +2 & +2 \\
Dry-Wet & -2 & +1 & $>+2$ & -2 to +2 & $<-2$ \\
Wet-Dry & +2 & -1 & $<-2$ & -2 to +2 & $>+2$ \\
\hline
\end{tabular}

\subsubsection{Parameter sensitivity test}

Since the governing condition (Eq. 5) shows that all $\alpha$ values between 0 and 1 satisfy the ETDI range (Table 1), parameter sensitivity test intended to investigate how do ETDI values change relative to various $\alpha$ and $\beta$ parameter combinations. Firstly, a sample of eleven $\alpha$ parameters from 0.0 to 1.0 at an interval of 0.1 were selected, and used to obtain corresponding $\beta$ values using Eq. (5). Secondly, the 8-days WSA values at point P1 (Fig. 1) were used to generate an ETDI curve for each parameter combination. Then, ETDI curves for all parameter combinations at point $\mathrm{P} 1$ were used in correlation analysis in order to investigate parameter combinations that have similar ETDI curves. Finally, estimation of drought events and total drought durations from ETDI curves at point P1 was also conducted in order to compare ETDI curves of different parameter combination with respect to drought characteristics. A drought event was identified by the start and the end of drought. The start of a drought event was the time when ETDI is less or equal to -1.00 for at least eight consecutive 8-days periods (approx. 2 months, Brito et al. 2018). The end of a drought event was the time when ETDI returns to zero (Spinoni et al. 2015). Total drought durations was the sum of all periods from all drought events in a time series.

\subsubsection{Temporal scale sensitivity test}


Sensitivity of ETDI at different temporal scales was done using a constant parameter combination in Eq. (4). The values of $\alpha$ and $\beta$ equal to 0.5 and 1, respectively, were selected as the appropriate parameter combination because they are in the middle of both parameter ranges. However, this parameter combination is also commonly used in estimation of ETDI (Bayissa et al. 2018; Narasimhan and Srinivasan 2005). Testing of sensitivity of ETDI at three different temporal scale was done by firstly, estimating ETDI curves of 8-days, 16-days and 1-month timesteps at each of the twelve points (P1 to P12) in the river basin. Then drought events and total drought durations at each point were computed in order to compare ETDI curves at different temporal scales with respect to drought characteristics. Here drought events for 8-days, 16-days and 1-month timesteps had at least eight consecutive 8-days periods, four consecutive 16-days periods and two consecutive months, respectively.

\section{Results and discussion}

\subsection{Parameter sensitivity}

In parameter sensitivity test, eleven parameter combinations resulted into eleven $\operatorname{ETDI}_{(\alpha, \beta)}$ time series. For illustration purposes, Fig. 4 only shows four of the eleven $\operatorname{ETDI}_{(\alpha, \beta)}$ curves. The $\operatorname{ETDI}_{(0.0,2.0)}$ curve was the widest in both dry (negative ETDI) and wet (positive ETDI) axes. The peaks of $\operatorname{ETDI}_{(0.1,1.8)}$ and $\operatorname{ETDI}_{(0.5,1.0)}$ curves were smaller than those of the $\operatorname{ETDI}_{(0.0,2.0)}$ curve. However, these three curves had similar patterns. On the other hand, the $\operatorname{ETDI}_{(0.9,0.2)}$ curve was very different from other curves due to its shorter and smoother peaks (Fig. 4). This is because the $\beta$-parameter of the curve was very small $(\beta=0.2)$, therefore, it diminished the influence of $\mathrm{WSA}_{\mathrm{t}}$ (Eq. 4). Unlike curves of other parameter combinations, the $\operatorname{ETDI}_{(1.0,0.0)}$ curve had zero values throughout the time series, thus coinciding with the time-axis (Fig. 4). Zero values occurred because $W_{S A}$ was nullified by the $\beta$-parameter which was equal to 0.0 , thus the $\operatorname{ETDI}_{(1.0,0.0)}$ curve depended only on $\operatorname{ETDI}_{\mathrm{t}-1}$ which was initially assumed zero (Eq. 4). In that case the $\operatorname{ETDI}_{(1.0,0.0)}$ curve was excluded in both correlation analysis and drought characterization.

ETDI $(\alpha, \beta)$ at point P1

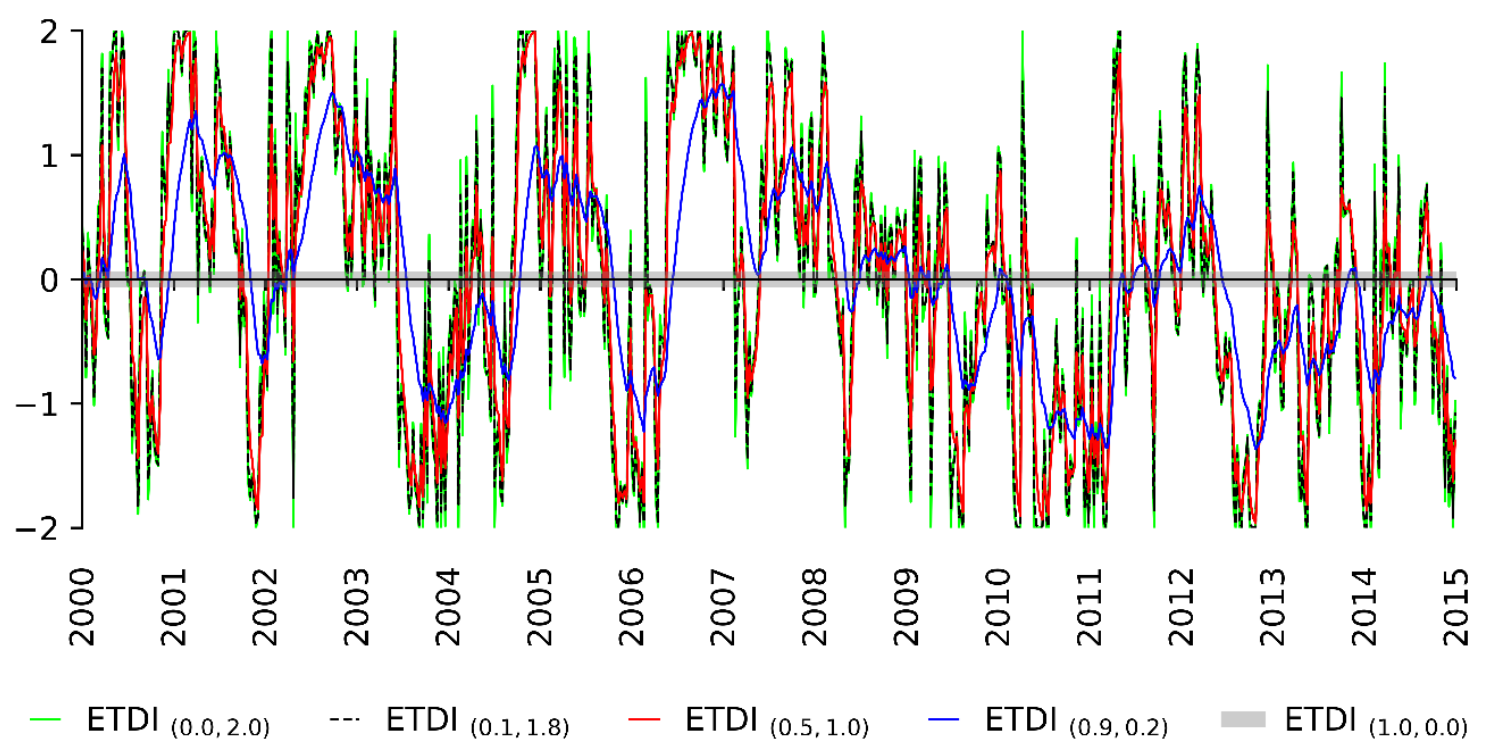

Fig. 4. The 8-days evapotranspiration deficit index (ETDI) for three different $(\alpha, \beta)$ parameters combinations at point P1 in the Ruvu River basin. 
Table 2: Correlation matrix of evapotranspiration deficit index (ETDI) at point P1 for various

$(\alpha, \beta)$-parameter combinations.

\begin{tabular}{llllllllll}
\hline \multirow{2}{*}{ Parameter } & $\begin{array}{l}\text { ETDI } \\
(0.0,2.0)\end{array}$ & $\begin{array}{c}\text { ETDI } \\
(0.1,1.8)\end{array}$ & $\begin{array}{c}\text { ETDI } \\
(0.2,1.6)\end{array}$ & $\begin{array}{c}\text { ETDI } \\
(0.3,1.4)\end{array}$ & $\begin{array}{c}\text { ETDI } \\
(0.4,1.2)\end{array}$ & $\begin{array}{c}\text { ETDI } \\
(0.5,1.0)\end{array}$ & $\begin{array}{c}\text { ETDI } \\
(0.6,0.8)\end{array}$ & $\begin{array}{c}\text { ETDI } \\
(0.7,0.6)\end{array}$ & $\begin{array}{c}\text { ETDI } \\
(0.8,0.4)\end{array}$ \\
\hline ETDI $_{(0.1,1.8)}$ & $\mathbf{1 . 0 0}$ & & & & & & & & \\
$\operatorname{ETDI}_{(0.2,1.6)}$ & 0.99 & 1.00 & & & & & & & \\
ETDI $_{(0.3,1.4)}$ & 0.98 & 0.99 & $\mathbf{1 . 0 0}$ & & & & & & \\
$\operatorname{ETDI}_{(0.4,1.2)}$ & 0.96 & 0.98 & 0.99 & 1.00 & & & & & \\
$\operatorname{ETDI}_{(0.5,1.0)}$ & 0.94 & 0.96 & 0.98 & 0.99 & $\mathbf{1 . 0 0}$ & & & & \\
$\operatorname{ETDI}_{(0.6,0.8)}$ & 0.91 & 0.93 & 0.95 & 0.97 & $\mathbf{0 . 9 8}$ & $\mathbf{1 . 0 0}$ & & & \\
$\operatorname{ETDI}_{(0.7,0.6)}$ & 0.86 & 0.89 & 0.91 & 0.94 & 0.96 & 0.98 & 0.99 & & \\
$\operatorname{ETDI}_{(0.8,0.4)}$ & 0.80 & 0.82 & 0.85 & 0.87 & 0.90 & 0.93 & 0.96 & $\mathbf{0 . 9 8}$ & \\
$\operatorname{ETDI}_{(0.9,0.2)}$ & 0.66 & 0.69 & 0.71 & 0.74 & 0.77 & 0.80 & 0.84 & 0.89 & 0.95 \\
\hline
\end{tabular}

Table 3: Drought events, total drought durations and duration per event at point P1 for various $(\alpha, \beta)$-parameter combinations.

\begin{tabular}{llll} 
& \multicolumn{3}{c}{ various $(\alpha, \beta)$-parameter combinations. } \\
\hline Parameter & Events & Total durations (month) & Duration per event (month) \\
\hline ETDI $_{(0.0,2.0)}$ & 11 & 42 & 4 \\
ETDI $_{(0.1,1.8)}$ & 10 & 38 & 4 \\
ETDI $_{(0.2,1.6)}$ & 8 & 39 & 5 \\
ETDI $_{(0.3,1.4)}$ & 8 & 41 & 5 \\
ETDI $_{(0.4,1.2)}$ & 10 & 47 & 5 \\
ETDI $_{(0.5,1.0)}$ & 10 & 51 & 5 \\
ETDI $_{(0.6,0.8)}$ & 10 & 51 & 5 \\
ETDI $_{(0.7,0.6)}$ & 9 & 50 & 6 \\
ETDI $_{(0.8,0.4)}$ & 9 & 54 & 6 \\
ETDI $_{(0.9,0.2)}$ & 4 & 40 & 10
\end{tabular}

The $\operatorname{ETDI}_{(0.0,2.0)}$ curve was highly correlated to the $\operatorname{ETDI}_{(0.1,1.8)}$ curve (Table 2), they both show the highest number of drought events, and the lowest duration per event (4 months per event, Table 3). This means that small $\alpha$-parameters of these two curves reduced the influence of $\mathrm{ETDI}_{\mathrm{t}-1}$ while large $\beta$-parameters allowed dominance of $\mathrm{WSA}_{\mathrm{t}}$ (Eq. 4). This is inversely demonstrated by the $\operatorname{ETDI}_{(0.9,0.2)}$ curve which had the lowest number of drought event and the highest duration per event (10 months per event, Table 3 ). Here, large $\alpha-$ parameter allowed dominance of $\mathrm{ETDI}_{\mathrm{t}-1}$, but small $\beta$-parameter had already smoothened peaks of $\mathrm{WSA}_{\mathrm{t}}$ (Eq. 4), thus causing wide but few peaks. In addition, the $\operatorname{ETDI}_{(0.9,0.2)}$ and $\operatorname{ETDI}_{(0.8,0.4)}$ curves were highly correlated (Table 2), but they had substantially different number of events and total drought durations (Table 3). High correlation between the two curves was due to similarity of their patterns which were not affected by minor parameter differences. However, the differences in drought characteristics were mainly due to the $\beta$ parameter, because it substantially reduced $\mathrm{WSA}_{\mathrm{t}}$ of the $\operatorname{ETDI}_{(0.9,0.2)}$ curve more than that of the $\operatorname{ETDI}_{(0.8,0.4)}$ curve. The $\operatorname{ETDI}_{(0.4,1.2)}$, and $\operatorname{ETDI}_{(0.6,0.8)}$ curves were highly correlated to the $\operatorname{ETDI}_{(0.5,1.0)}$ curve and had equal number of drought events (Tables 2 and 3), this means 
that the influence of their $\mathrm{ETDI}_{\mathrm{t}-1}$ and $\mathrm{WSA}_{\mathrm{t}}$ were reduced to almost half by $\alpha$-parameters but after being almost fully allowed by $\beta$-parameters (Eq. 4), respectively.

Generally, as the $(\alpha, \beta)$-parameters deviated from the midpoint $(0.5,1.0)$ towards endpoint $(0.0,2.0)$, the $\operatorname{ETDI}_{(0.0,2.0)}$ curve depended mostly on $\mathrm{WSA}_{t}$ while $\operatorname{ETDI}_{\mathrm{t}-1}$ became substantially diminished (Eq. 4, Fig. 3). When $(\alpha, \beta)$-parameters equalled $(0.0,2.0)$, $\operatorname{ETDI}_{(0.0,2.0)}$ curve did not substantially differ from that of the mid-point. That is why the correlation coefficient of the $\operatorname{ETDI}_{(0.0,2.0)}$ and mid-point curves was still very high $(94 \%$, Table 2) and drought durations per event had minor differences (Table 3). As $(\alpha, \beta)$ parameters approached $(0.9,0.2)$, ETDI $_{(0.9,0.2)}$ curve deviated substantially from that of the mid-point. The correlation coefficient was very small, (66\%, Table 2) and drought durations per event differed by 5 months (Table 3 ). This deviation was caused by diminishing $\mathrm{WSA}_{\mathrm{t}}$ due to declining $\beta$-parameter (Eqs. 4 and 5 ). This indicates that the $\beta$-parameter is more influential than the $\alpha$-parameter because it controls strong signal from $\mathrm{WSA}_{\mathrm{t}}$ whereas the latter modulates long-term memory of $\mathrm{ETDI}_{\mathrm{t}-1}$, which also originates from $\mathrm{WSA}_{\mathrm{t}}$.

Therefore, an arbitrary choice of a parameter combination has drastic effects on drought characteristics. As the result, information about drought frequency, severity and intensity can be misrepresented, leading to inappropriate intervention measures for mitigation or adaptation to drought. However, the mid-point is not the best parameter combination, because the contributions of $\mathrm{ETDI}_{\mathrm{t}-1}$ and $\mathrm{WSA}_{\mathrm{t}}$ may be varying from region to region even from season to season. This uncertainty in selection of an appropriate parameter combination is enormous because the range between the endpoints (See Fig. 3) can be sub-divided into many parameter combinations depending on the required level of accuracy, i.e., decimal places. On the other hand, the endpoints, i.e., $(0.0,2.0)$ and $(1.0,0.0)$ are also not realistic because they neglect contributions of ETDI $\mathrm{t}_{-1}$ and $\mathrm{WSA}_{\mathrm{t}}$, respectively. However, like coefficients of the Palmer drought severity index, the coefficients of ETDI might also be derived from local characteristics in a particular area (Karl 1986; Palmer 1965; Sivakumar et al. 2011). Apart from that, the comparisons of ETDI time series with other drought indices could also be used to calibrate the ETDI coefficients (John et al. 2013).

\subsection{Temporal scale sensitivity}

For illustration purposes, only ETDI curves of points P1 to P6 are presented, the rest of the points are summarized in Table 4. The 8-days, 16-days and 1-month time scales caused substantially different ETDI curves at the points in the Ruvu River basin (Figs. 5 and 6). At all points, 8-days ETDI curves were the widest in both dry (negative ETDI) and wet (positive ETDI) axes. Thus, 16-days ETDI curves were enclosed by 8-days ETDI curves throughout the time series. Similarly, the monthly ETDI curves were also enclosed by both 8-days ETDI and 16-days ETDI curves. These ETDI curves showed that the effects of aggregation of ET and PET from small to large time scales were propagated to the ETDI values (cf. Figs. 2, 5 and 6).

At all twelve points in the river basin, the number of drought events decreased as the size of time scales increased (Table 4). The difference in number of drought events between consecutive time scales was mainly between 1 and 2 except at points P4 and P11 where the differences between 16-days and 1-month time scales were relatively large (about 5 drought events). The large differences in drought events could be attributed to local effects because the two points are found in the northern part of the river basin (cf. Fig. 1). 
Table 4: Drought events, total drought durations and duration per event at points P1 to P12 at 8-days,

16-days and 1-month temporal scales in the River River basin.

\begin{tabular}{|c|c|c|c|c|}
\hline Point & Timeseries & Events & Total durations (months) & Duration per event (months) \\
\hline \multirow{3}{*}{ P1 } & 8 -days & 10 & 51 & 5 \\
\hline & 16-days & 9 & 29 & 3 \\
\hline & 1-month & 8 & 17 & 2 \\
\hline \multirow{3}{*}{$\mathrm{P} 2$} & 8 -days & 7 & 33 & 5 \\
\hline & 16-days & 5 & 16 & 3 \\
\hline & 1-month & 5 & 9 & 2 \\
\hline \multirow{3}{*}{ P3 } & 8 -days & 10 & 59 & 6 \\
\hline & 16-days & 9 & 31 & 3 \\
\hline & 1-month & 8 & 16 & 2 \\
\hline \multirow{3}{*}{ P4 } & 8 -days & 7 & 51 & 7 \\
\hline & 16-days & 7 & 31 & 4 \\
\hline & 1-month & 2 & 15 & 7 \\
\hline \multirow{3}{*}{ P5 } & 8 -days & 9 & 46 & 5 \\
\hline & 16-days & 10 & 29 & 3 \\
\hline & 1-month & 9 & 15 & 2 \\
\hline \multirow{3}{*}{ P6 } & 8-days & 11 & 54 & 5 \\
\hline & 16-days & 11 & 29 & 3 \\
\hline & 1-month & 8 & 12 & 2 \\
\hline \multirow{3}{*}{ P7 } & 8-days & 11 & 59 & 5 \\
\hline & 16-days & 9 & 30 & 3 \\
\hline & 1-month & 7 & 13 & 2 \\
\hline \multirow{3}{*}{ P8 } & 8-days & 9 & 59 & 7 \\
\hline & 16-days & 7 & 30 & 4 \\
\hline & 1-month & 6 & 15 & 3 \\
\hline \multirow{3}{*}{ P9 } & 8-days & 8 & 63 & 8 \\
\hline & 16-days & 8 & 30 & 4 \\
\hline & 1-month & 5 & 14 & 3 \\
\hline \multirow{3}{*}{ P10 } & 8-days & 9 & 54 & 6 \\
\hline & 16-days & 7 & 26 & 4 \\
\hline & 1-month & 8 & 14 & 2 \\
\hline \multirow{3}{*}{ P11 } & 8-days & 14 & 52 & 4 \\
\hline & 16-days & 12 & 30 & 3 \\
\hline & 1-month & 7 & 17 & 2 \\
\hline \multirow{3}{*}{$\mathrm{P} 12$} & 8-days & 15 & 54 & 4 \\
\hline & 16-days & 11 & 32 & 3 \\
\hline & 1-month & 9 & 17 & 2 \\
\hline
\end{tabular}

Although differences between numbers of drought events were not too large, their corresponding total drought durations differed by very large number of months (Table 4). The total drought durations of 8-days ETDI curves were almost two-times and three-times those of 16-days ETDI curves and monthly ETDI curves, respectively. Thus, total drought durations decreased as the size of time scales increased. Moreover, almost all points in the river basin had duration per event ranging from 5 months for 8-days ETDI curves to 2 months for monthly ETDI curves (Table 4). 
ETDI $(\alpha=0.5, \beta=1.0)$ for three temporal scales
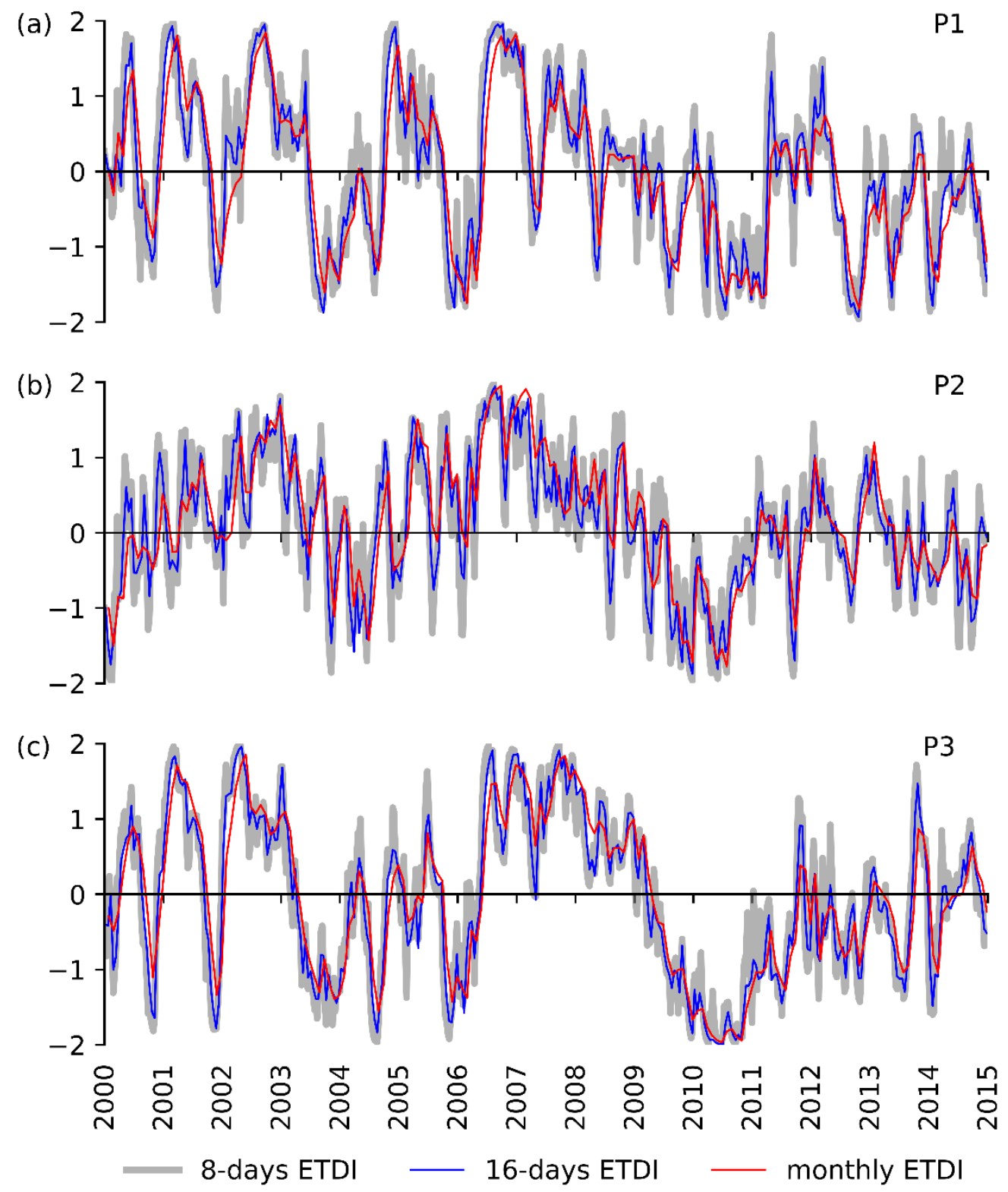

Fig. 5. Evapotranspiration deficit index (ETDI) at 8-days, 16-days and 1-month temporal scales at points P1 to P3 in the Ruvu River basin. 
$\operatorname{ETDI}(\alpha=0.5, \beta=1.0)$ for three temporal scales
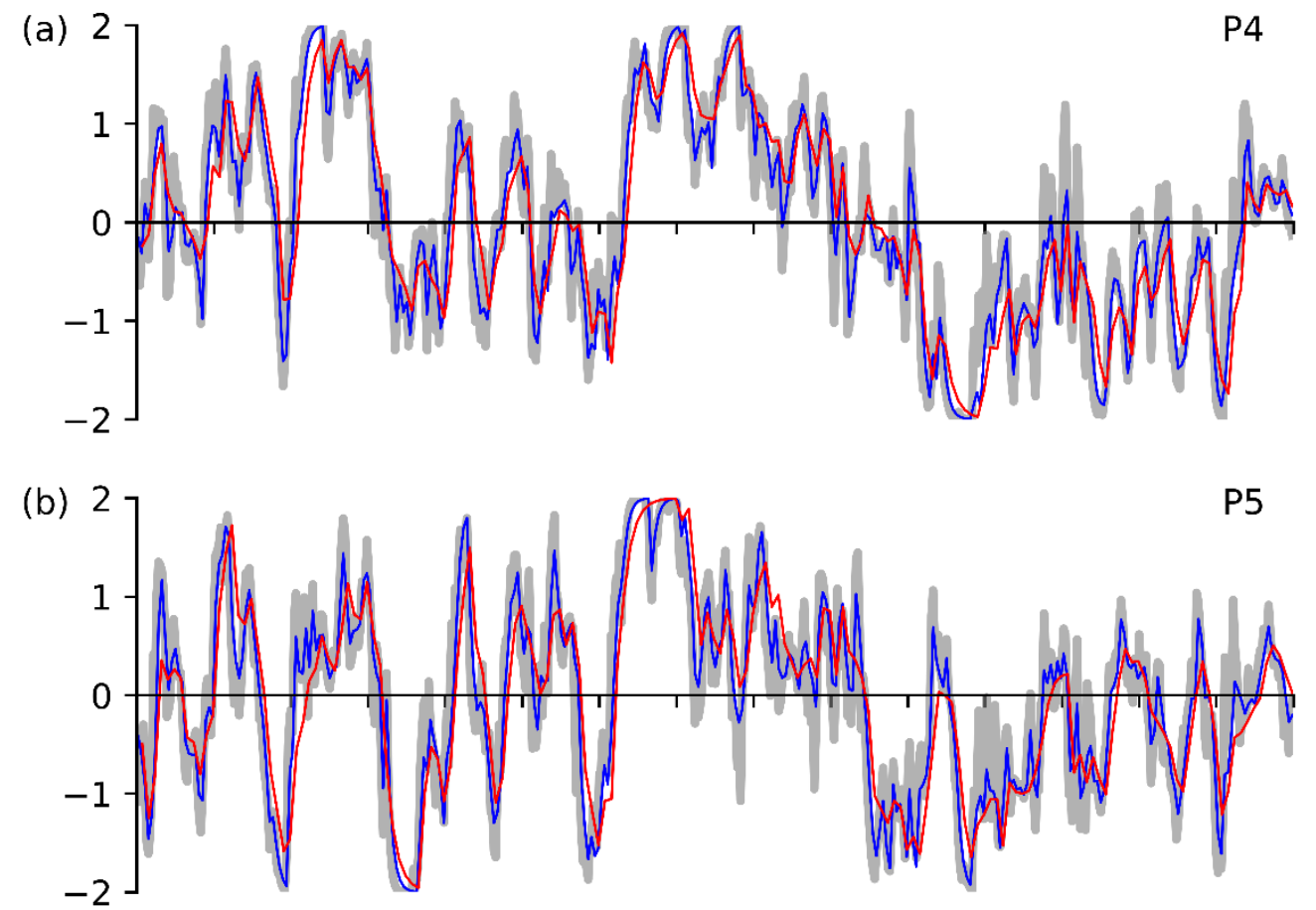

(c)

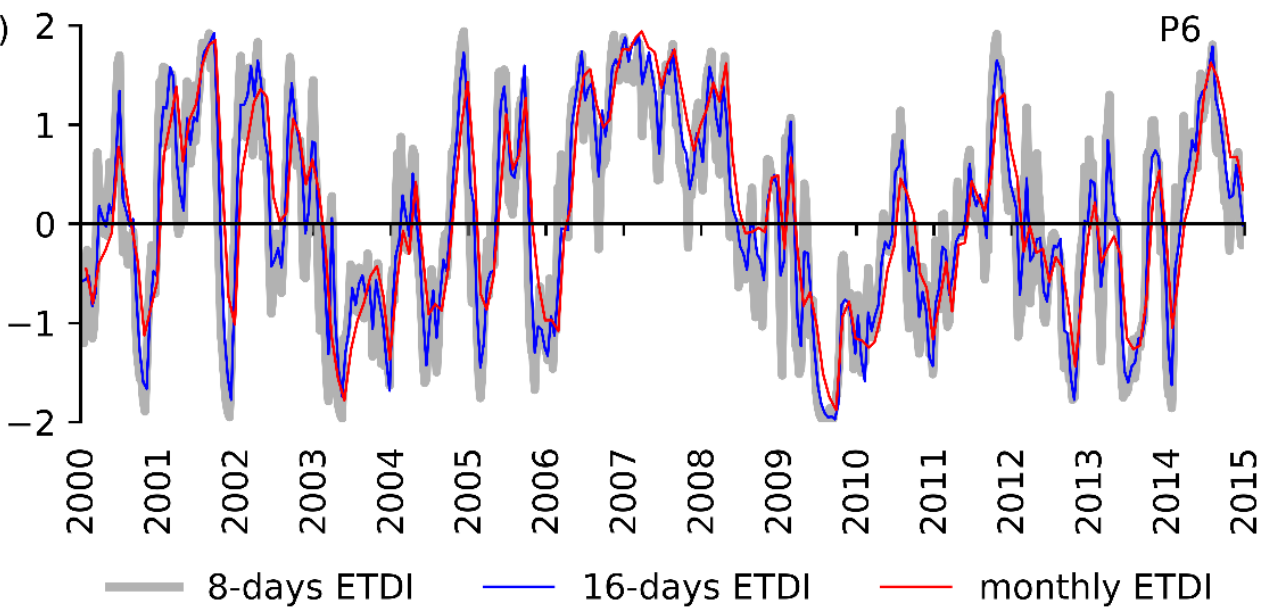

Fig. 6. Evapotranspiration deficit index (ETDI) at 8-days, 16-days and 1-month temporal scales at points P4 to P6 in the Ruvu River basin.

Since different number of drought events and drought durations usually leads to different drought severity and drought intensity (Brito et al. 2018; Hao and Singh 2015; Hassan et al. 2014), therefore, different time scales of ET and PET data also lead to different ETDI and consequently different drought characteristics. By using standardized precipitation index and effective drought index, Jain et al. (2015) also found that drought characteristics vary too much with different time scales. Moreover, Ntale and Gan (2003) argued that there are no objective rules to select an appropriate time scale. However, small drought duration per event in this study, indicates that small time scales can be useful because a region suffering from drought can return to normal with only a few days rainfall (Byun and Wilhite 1999). 


\section{Conclusions}

This study used MODIS ET time series from twelve points spatially distributed in the Ruvu River basin to test sensitivity of ETDI to its parameters and temporal scales. Parameter sensitivity test revealed that ETDI is less sensitive when the $(\alpha, \beta)$-parameters ranges from $(0.1,1.8)$ to $(0.5,1.0)$ inclusive, and more sensitive when they approach $(0.9,0.2)$. Since ETDI is sensitive to different parameter combinations, the selection of an appropriate parameter combination might rely on information from specific locations. Moreover, an appropriate parameter combination can also be obtained when ETDI is compared against other drought indices. Therefore, in reducing uncertainty of selecting an appropriate parameter combination, the general ETDI formula might require parameter calibration. Temporal scales sensitivity test at twelve points in the river basin showed that the number of drought events, the total drought durations and durations per event decreases as temporal scales increases. However, there is no objective rule on an appropriate temporal scale to be used in ETDI estimation prior to drought characterization. Therefore, small time scale ET datasets are highly recommended in order to increase accuracy of drought characteristics developed from ETDI.

\section{Appendix A.}

The specific ETDI formula (Eq. A1: Narasimhan and Srinivasan 2005). Where, the subscript $t$ represents a continous timestep. $\alpha$ represents fraction of the $\mathrm{ETDI}_{\mathrm{t}-1}$ that contributes to ETDI $_{\mathrm{t}}$.

$$
\mathrm{ETDI}_{\mathrm{t}}=\alpha \mathrm{ETDI}_{\mathrm{t}-1}+\mathrm{WSA}_{\mathrm{t}}
$$

If ETDI is scaled between -2 and +2 , at a boundary condition (i.e., very dry condition), WSA equals to -1 , both ETDI $_{t}$ and ETDI $_{t-1}$ equal to -2 . By substituting WSA and ETDI values in Eq. (A1), $\alpha$ becomes equal to 0.5. The final specific ETDI formula is shown in Eq. (A2). The value of ETDI ranges between -2 and +2 indicating very dry and very wet conditions, respectively.

$$
\mathrm{ETDI}_{\mathrm{t}}=0.5 \mathrm{ETDI}_{\mathrm{t}-1}+\mathrm{WSA}_{\mathrm{t}}
$$

\section{Acknowledgements}

The author would like to thank the maintainer of the NTSG repository for freely providing MODIS ET datasets. Thanks to Sekela Twisa from the United Nations University-Institute for Integrated Management of Material Fluxes and of Resources (Germany), and Festo Silungwe from the Humboldt Universität zu Berlin (Germany) for proofreading the manuscript.

\section{References}

Ali M, Omid M, Amir A (2015) A hybrid framework for assessing socioeconomic drought: Linking climate variability, local resilience, and demand Journal of Geophysical Research: Atmospheres 120:7520-7533 doi:doi:10.1002/2015JD023147 
Bayissa Y, Maskey S, Tadesse T, van Andel S, Moges S, van Griensven A, Solomatine D (2018) Comparison of the Performance of Six Drought Indices in Characterizing Historical Drought for the Upper Blue Nile Basin, Ethiopia Geosciences 8:81

Brito SSB, Cunha APMA, Cunningham CC, Alvalá RC, Marengo JA, Carvalho MA (2018) Frequency, duration and severity of drought in the Semiarid Northeast Brazil region Int J Climatol 38:517-529 doi:doi:10.1002/joc.5225

Byun H-R, Wilhite DA (1999) Objective Quantification of Drought Severity and Duration Journal of Climate 12:2747-2756 doi:10.1175/15200442(1999)012<2747:OQODSA>2.0.CO;2

Esfahanian E, Nejadhashemi AP, Abouali M, Adhikari U, Zhang Z, Daneshvar F, Herman MR (2017) Development and evaluation of a comprehensive drought index J Environ Manage 185:31-43 doi:https://doi.org/10.1016/j.jenvman.2016.10.050

Hao Z, Singh VP (2015) Drought characterization from a multivariate perspective: A review J Hydrol 527:668-678 doi:https://doi.org/10.1016/j.jhydrol.2015.05.031

Hassan IH, Mdemu MV, Shemdoe RS, Stordal F (2014) Drought pattern along the coastal forest zone of Tanzania Atmospheric and Climate Sciences 4:369-384 doi:10.4236/acs.2014.43037

Jain VK, Pandey RP, Jain MK, Byun H-R (2015) Comparison of drought indices for appraisal of drought characteristics in the Ken River Basin Weather and Climate Extremes 8:1-11 doi:https://doi.org/10.1016/j.wace.2015.05.002

Jarvis A, Reuter HI, Nelson A, Guevara E (2008) Hole-filled SRTM for the globe Version 4 Available from the CGIAR-CSI SRTM 90m Database (http://srtmcsicgiarorg)

John J, Debra P, Lyons DL, George H (2013) A tool for calculating the Palmer drought indices Water Resour Res 49:6086-6089 doi:doi:10.1002/wrcr.20342

Karl TR (1986) The Sensitivity of the Palmer Drought Severity Index and Palmer's Z-Index to their Calibration Coefficients Including Potential Evapotranspiration Journal of Climate and Applied Meteorology 25:77-86 doi:10.1175/15200450(1986)025<0077:tsotpd>2.0.co;2

Kashaigili JJ (2011) Rapid environmental flow assessment for the Ruvu River. iWASH,

Li JZ, Wang YX, Li SF, Hu R (2015) A Nonstationary Standardized Precipitation Index incorporating climate indices as covariates Journal of Geophysical Research: Atmospheres 120:12,082-012,095 doi:doi:10.1002/2015JD023920

Martínez-Fernández J, González-Zamora A, Sánchez N, Gumuzzio A (2015) A soil water based index as a suitable agricultural drought indicator J Hydrol 522:265-273 doi:https://doi.org/10.1016/j.jhydrol.2014.12.051

Martínez-Fernández J, González-Zamora A, Sánchez N, Gumuzzio A, Herrero-Jiménez CM (2016) Satellite soil moisture for agricultural drought monitoring: Assessment of the SMOS derived Soil Water Deficit Index Remote Sens Environ 177:277-286 doi:https://doi.org/10.1016/j.rse.2016.02.064 
McKee T, Doesken N, Kleist J (1993) The relationship of drought frequency and duration to time scales Eighth Conference on Applied Climatology doi:citeulike-articleid: 14027580

Mu Q, Zhao M, Running SW (2011) Improvements to a MODIS global terrestrial evapotranspiration algorithm Remote Sens Environ 115:1781-1800 doi:10.1016/j.rse.2011.02.019

Narasimhan B, Srinivasan R (2005) Development and evaluation of Soil Moisture Deficit Index (SMDI) and Evapotranspiration Deficit Index (ETDI) for agricultural drought monitoring Agric $\quad$ For $\quad$ Meteorol 133:69-88 doi:https://doi.org/10.1016/j.agrformet.2005.07.012

Ntale HK, Gan TY (2003) Drought indices and their application to East Africa Int J Climatol 23:1335-1357 doi:10.1002/joc.931

Palmer WC (1965) Meteorological Drought vol 30. US Department of Commerce Weather Bureau, Washington DC

Panu US, Sharma TC (2002) Challenges in drought research: some perspectives and future directions Hydrol Sci J 47:S19-S30 doi:10.1080/02626660209493019

Pramudya Y, Onishi T (2018) Assessment of the Standardized Precipitation Index (SPI) in Tegal City, Central Java, Indonesia IOP Conference Series: Earth and Environmental Science 129:012019

Šebenik U, Brilly M, Šraj M (2017) Drought Analysis Using the Standardized Precipitation Index (SPI) 201757 doi:10.3986/ags.729

Shah R, Bharadiya N, Manekar V (2015) Drought Index Computation Using Standardized Precipitation Index (SPI) Method For Surat District, Gujarat Aquatic Procedia 4:1243-1249 doi:https://doi.org/10.1016/j.aqpro.2015.02.162

Sivakumar MVK, Motha RP, Wilhite DA, Wood DA Agricultural Drought Indices. In: Proceedings of the WMO/UNISDR Expert Group Meeting on Agricultural Drought Indices, 2-4 June 2010, Murcia, Spain: Geneva, Switzerland: World Meteorological Organization. AGM-11, WMO/TD No. 1572; WAOB-2011. 197 pp., 2011.

Spinoni J, Naumann G, Vogt J, Barbosa P (2015) European drought climatologies and trends based on a multi-indicator approach Global and Planetary Change 127:50-57 doi:https://doi.org/10.1016/j.gloplacha.2015.01.012

Touma D, Ashfaq M, Nayak MA, Kao S-C, Diffenbaugh NS (2015) A multi-model and multi-index evaluation of drought characteristics in the 21st century $\mathbf{J}$ Hydrol 526:196-207 doi:https://doi.org/10.1016/j.jhydrol.2014.12.011

Trambauer P, Maskey S, Werner M, Pappenberger F, van Beek LPH, Uhlenbrook S (2014) Identification and simulation of space-time variability of past hydrological drought events in the Limpopo River basin, southern Africa Hydrol Earth Syst Sci 18:29252942 doi:10.5194/hess-18-2925-2014 
Wilhite DA, Svoboda MD, Hayes MJ (2007) Understanding the complex impacts of drought: A key to enhancing drought mitigation and preparedness Water Resour Manage 21:763-774 doi:10.1007/s11269-006-9076-5

Yang H, Wang H, Fu G, Yan H, Zhao P, Ma M (2017) A modified soil water deficit index (MSWDI) for agricultural drought monitoring: Case study of Songnen Plain, China Agric Water Manage 194:125-138 doi:https://doi.org/10.1016/j.agwat.2017.07.022

450

Zargar A, Sadiq R, Naser B, Khan FI (2011) A review of drought indices Environmental Reviews 19:333-349 doi:10.1139/a11-013

Ziolkowska J (2016) Socio-Economic Implications of Drought in the Agricultural Sector and the State Economy Economies 4:19 